دراسة اقتصادية للسوق العالمى للذرة الصفراء مع الإثارة الى سوق الذرة الصفراء المصري

$$
\text { منى كمال رياض عبد الكريم }
$$

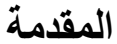

تحتوى الذرة الثامية البيضاء منها و الصفراء على نفس التزكيب بوجه عام، فيما عدا زيادة فى محتوى الذرة الثامية

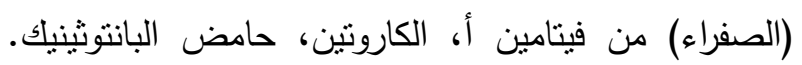

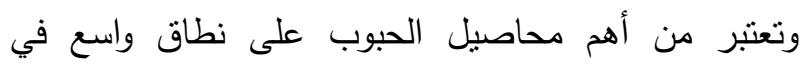
العالم، حيث تمثل الذرة الثامية المرتبة الثالثة من حيث

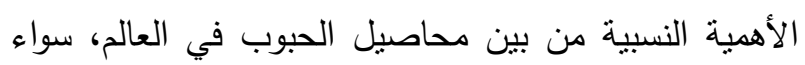
من حيث المساحة المزروعة أو جملة الإنتاج العالمي وذلك فئل العاكي

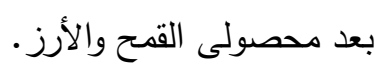

وتستخدم الذرة الصفراء فى تغذية الإنسان بصفة عامة،

ولكن الاهم أنها نستخدم في تغذية الحيوان، حيث تعتبر الذرة الثنامية الصفراء أهم محاصيل الحبوب التي تستخدم في هذا

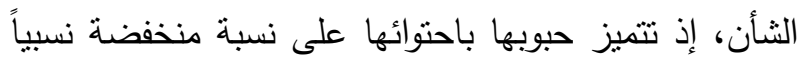
من الألياف، ومن ثم فتعتبر عليقة مركزة جيدة في تغذية

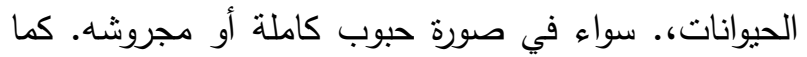
تتميز الذرة الصفراء أكثر كفاءة في زيادة وزن الحيوانات بالإضافة الى مساهنتها في زيادة انتاج الالبان والبيض بالمقارنة ومثيلتها البيضاء. وتستخدم أيضا مخلفات طحنها في تغذية الحيوانات. كما تستخدم كعلف أخضر للحيوانات،

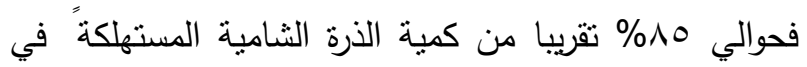

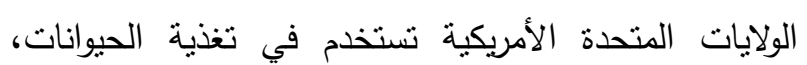

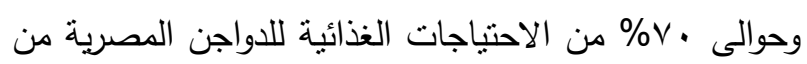
العلف تغطى من الذرة الصفراء.
الملخص العربى

أستهدف البحث بصفة أساسية دراسة طبيعة ووصف السوق العالمى للارة الصفراء للتعرف على نوع السوق وتكوينه ومن المتحكم في وضح سياساته السعرية، حتى يتمكن متذذى القرار من وضع اليات مناسبة للسياسات التجارية والإنتاجية. أهم النتائج المستخلصة: 1 - أن سوق الذرة الصفراء العالمى يعتبر سوق أحتكار قلة وأن أمريكا والبرازيل والأرجنتين وأوكرانيا يمثلون الكارتل ولكن غير الكير رسمي ، وأن القيادة السعرية لامريكا والبرازيل والأرجنتين واوكرانيا مجتمعة والذى يمثل متوسط كمية صادرتهم من الذرة الصفراء حوالى צ7\% تقريبا من اجمالى كمية صادرات العالم

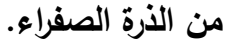

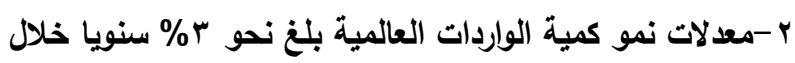
فترة الدراسة، في حين أن هذا المعدل في كمية واردات مصر العرات

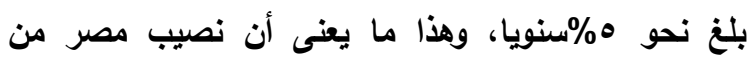

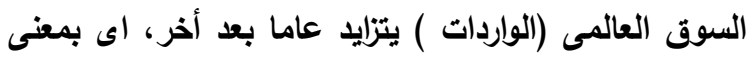

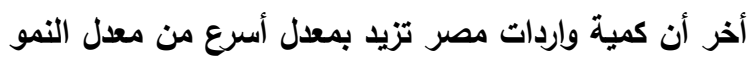
العالمى، وهو ما أوضحته معادلات الاتجاه الزمنى العام للواردات المصرية والعالمية . ץ-أن أوكرانيا كدولة مصدرة للذرة الصفراء المصرية تعد المصدر

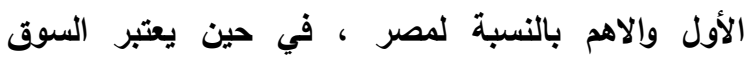

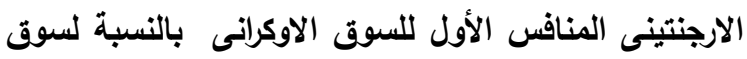

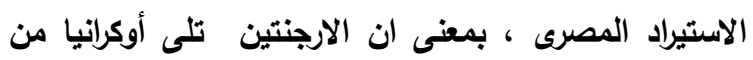

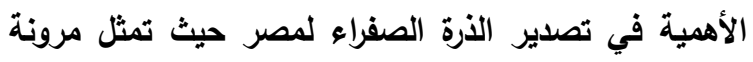

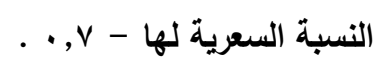
الكلمات المفتاحية : الأرة - الأسعار - السوق - العالمى. 


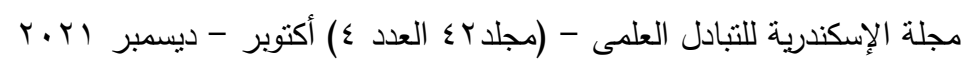

r-محاولة أقتراح بعض السياسات السعرية والإنتاجية والتجارية لمواجهة تغيرات السوق العالمى للذرة الصفراء.

\section{الطريقة البحثية}

استخدم البحث أسلوب التحليل الوصفي، بالإضافة إلى أسلوب التحليل الكمّي باستخدام بعض النماذج الرياضية المختلفة مثل الاتجاه العام، و تقدير بعض نماذج الانحدار

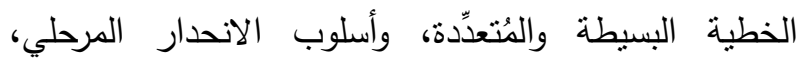
ومصفوفة مُعاملات الارنباط لتقدير دوال الطلب للمحصول موضع الدراسة، كما استخدم البحث بعض المؤشرات الإحصائية البسيطة منل النسب المئوية ، والمتوسطات، ومعدلات النمو. ذللك بالإضافة الى أستخدام النظرية الاقتصادية في توصيف طبيعة السوق العالمى والمصرى للذرة الصفراء.

\section{النتائج البحثية}

أولا : الإنتاج العالمى والمصرى من الأرة الصفراء يتبين من الجدول(1) أن كل من الإنتاج العالمى والمصرى من الذرة الصفراء يتزايد بنسب متفاوتة خلال الفترة

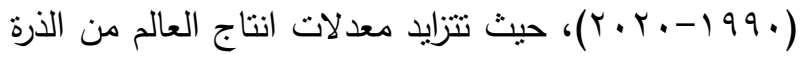

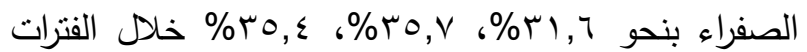

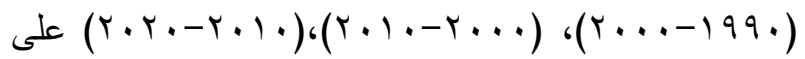

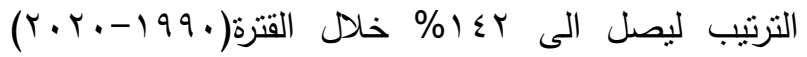
وترجع هذه الزيادة بالضرورة الى التقدم العلمي في مجال تحسين السلالات والهندسة الجينية ومكافحة الحشرات والأسمدة وطرق الزراعة والحصاد وخطط الإستثمار والتتمية

عالميا.

في حين تتزايد معدلات انتاج مصر من الذرة الصفراء

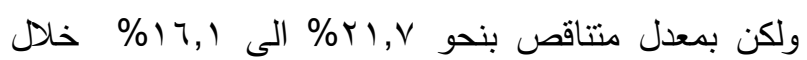

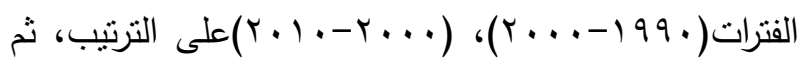

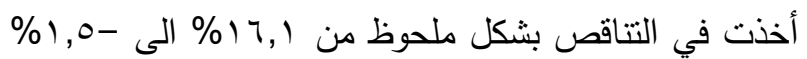

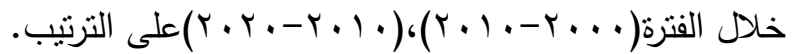

\section{المشكلة البحثية}

تتلخص مشكلة البحث في أنه بالرغم من أهمية الذرة الصفراء في تغذية الحيوانات وخاصة الدواجن، بالإضافة الى بلى ما تشهده مصر في الفترات الحالية منذ أكتوبر • r. . من ارتفاع في أسعار الدواجن والبيض، الا أن معظم الدراسات التي تتاولت الذرة الصفراء قد ركزت على جانب الإنتاج، مع الاشارة للتجارة الخارجية، بالرغم من أن العجز في الإنتاج المحلى من الذرة الصفراء يؤدى بطبيعة الحال الى زيادة

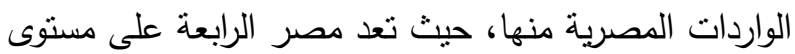
العالم في اسنيراد الذرة الصفراء حيث قدرت منوسط كمية واردتها منها بحوالي rr, • 1 مليون طن من أجمالى واردات

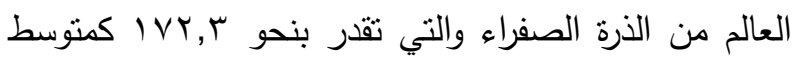

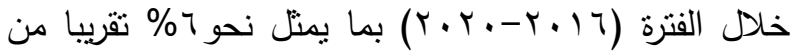
أجمالى واردات العالم منها لنفس الفترة، الامر الذى يجعل مصر من أكثر الدول تأثرا بالتغيرات العالمية في شكل ومحتوى السوق العالمى للذرة الصفراء جمعت وحسبت من بيانات شبكة الانترنت التابعة WWW.Trade map.org.eg

\section{الأهداف البحثية}

يستهدف البحث بصفة أساسية دراسة طبيعة ووصف السوق العالمى للذرة الصفراء للتعرف على نوع السوق وتكوينه ومن المتحكم في وضع سياساته السعرية، حتى يتمكن متخذى القرار من وضع اليات مناسبة للسياسات التجارية والإنتاجية، نظرا لان السوق المحلى يعتمد بشكل

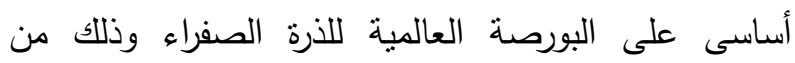

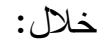

ا-توصيف السوق العالمى للذرة الصفراء، ومن ثم دراسة كيفية التعامل معه.

Y-دراسة محددات الطلب المصرى من الذرة الصفراء بالأسواق الخارجية للدول المصدرة الرئيسية، واستخراج المرونات وتفسير نتائجها. 


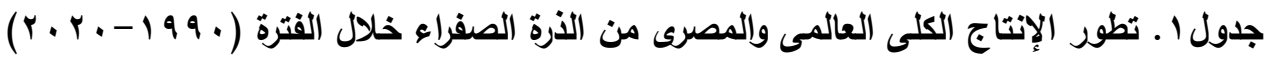
( الإنتاج بالمليون طن )

\begin{tabular}{|c|c|c|c|c|c|c|c|c|}
\hline 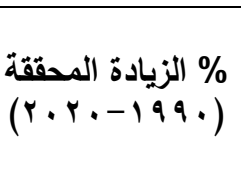 & 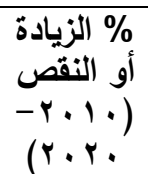 & 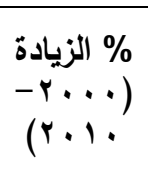 & 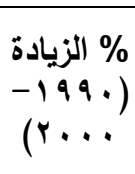 & الإنتاج & الإنتاج & الإنتاج & $\begin{array}{l}\text { الإنتاج } \\
\text { أو9. }\end{array}$ & الإنتاج \\
\hline$\% 1 \leq r$ & $\%$ \% , ร & $\%$ \% , v & $\%$ \% & $111 \mathrm{~V}$ & Nro & 7.1 & $\Sigma T Y$ & العالمى \\
\hline \multirow[t]{2}{*}{$\% r q, 1$} & $\% 1,0-$ & $\% \backslash 7,1$ & $\%$ Y , V & $7, \Sigma$ & 7,0 & 0,7 & $\varepsilon, 7$ & المصرى \\
\hline & & & & $\% \cdot, 7$ & $\% \cdot, \vee q$ & $\% \cdot, 9 r$ & $\% \cdot, 99$ & \\
\hline
\end{tabular}

المصدر : تقارير مجلس الحبوب الدولي IGC

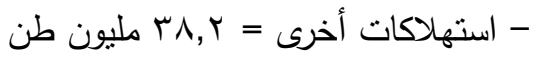

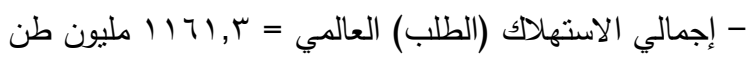

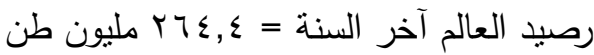

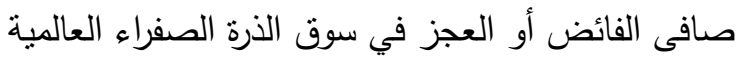

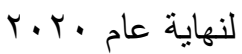

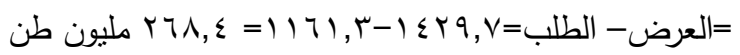
(مجلس الحبوب الدولي GMR517 يناير (Y. (م) ) من العرض السابق لتحليل العرض والطلب للسوق

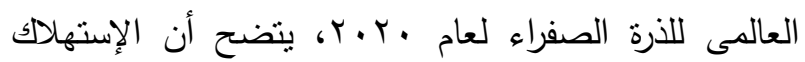
العالمي خلال السنة قد تجاوز الإنتاج العالمي بحوالي

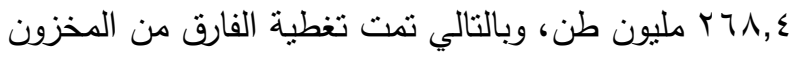
العالمي مما أدى الى انخفاض مخزون الإحتياطي العالمي بمقدار ب,r, مليون طن وهو ما قد يساهم بشكل كبير في

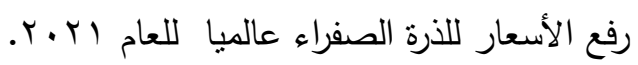
ثالثا: توصيف السوق العالمى للأرة الصفراء أ- واردات العالم من الذرة الصفراء : تشير بيانات الجدول رقم (r) الى أن اليابان احتلت

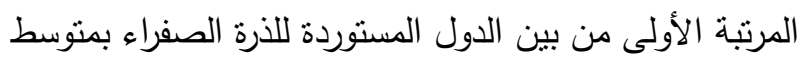

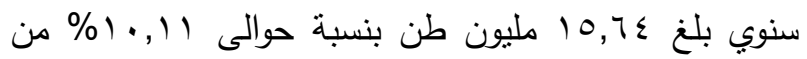
أجمالى صادرات العالم من الذرة الصفراء خلص الفترة
ليكون معدل الزيادة في الإنتاج المصرى من الذرة الصفراء

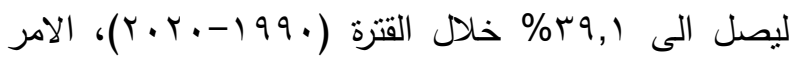
الذى يوضتح ارتفاع انتاج الذرة الصفراء المصرية ولكن بمعدلات متتاقصة خاصة العشر سنوات الأخيرة بالرغم من زيادة المساحات المزروعة منها، ولكن قد برجع هذا الى ضرورة أستخدام أصناف عالية الجودة ترفع من معدلات الإنتاجية، إضافة الى زيادة دعم المزارعين في شرائهم لتقاوى عالية الإنتاجية وبأسعار مناسبة تنتاسب مع ظروفه الاقتصادية.

ثانيا: تحليل العرض والطلب العالمى للأرة الصفراء لعام $r \cdot r$. 1 - العرض العالمى من الأرة الصفراء

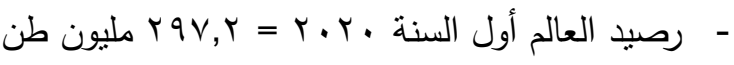

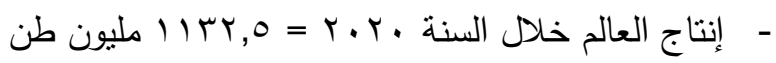
- - إجمالي الإنتاج والمخزون (العرض ) العالمي من الذرة

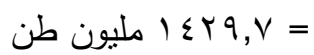
r- الإستهلاك العالمي من الأرة الصفراء

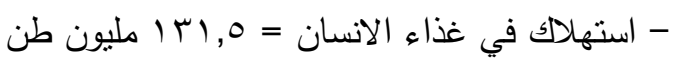

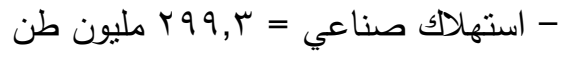
- استهلاك في اعلاف الحيوانات = r, r9 مليون طن 
وبأصناف عالية الجودة، وهذا لا يتأتى الا من خلال الزراعات التعاقدية.

ب- صادرات العالم من الأرة الصفراء تشير بيانات الجدول رقم (r) الى أن أمريكا احتلت

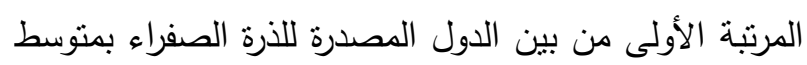

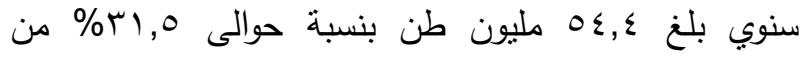
أجمالى صادرات العالم من الذرة الصفراء خلاء له الفترة

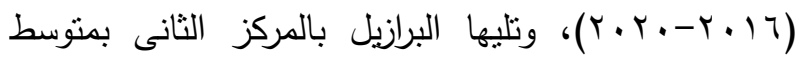
سنوي بلغ 0, •r مليون طن بنسبة حوالى IV\%، وتليها

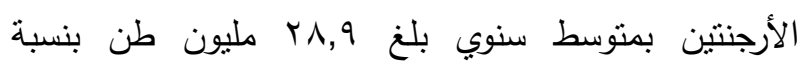

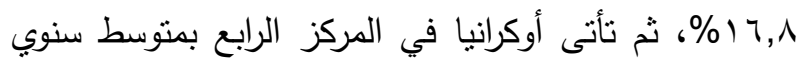

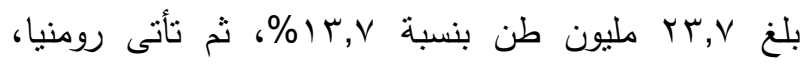

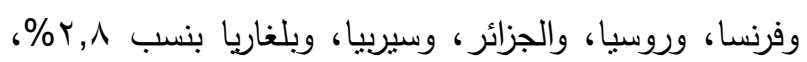

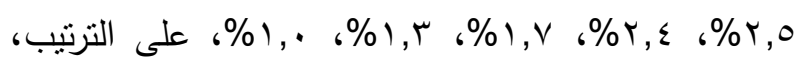

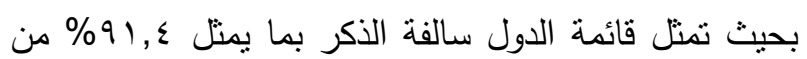
جملة صادرات العالم من الذرة الصفراء .

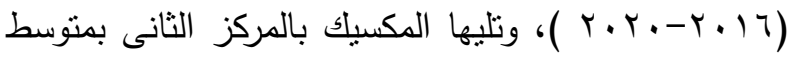

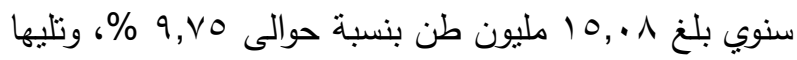

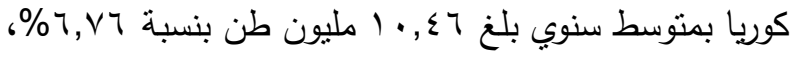
ثم نأتى مصر في المركز الرابع اسنيرادا للذرة الصفراء

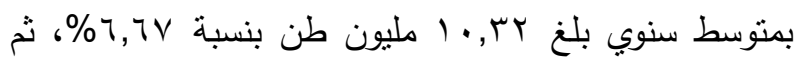

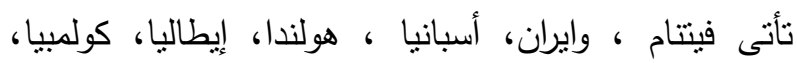

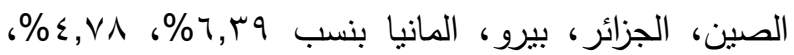

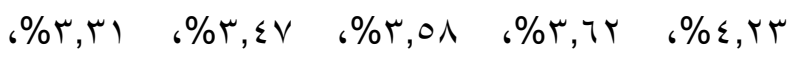
r

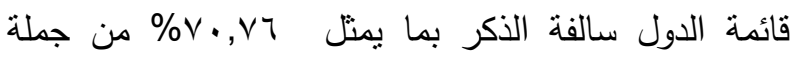
واردات العالم من الذرة الصفراء. .

الامر الذى يعتبر بمثابة تحدى كبير نحو كيفية التقليل من حجم الواردات من الذرة الصفراء، حيث تستورد مصر الهر بنحو 0٪\% من احتياجاتها من الذرة الصفراء، الامر الذى يتطلب البحث في إمكانية رفع معدلات الإنتاج المحلى من من من مأن خلال اتباع بعض السياسات المناسبة التي من شأنها تشجيع المزارعين على زراعة مساحات اكبر من الذرة الصفراء

جدول r ـ الأهمية النسبية لاهم الدول المستوردة للأرة الصفراء من حيث الكمية المستوردة منها في العالم خلال الفترة (الكمية بالمليون طن )

\begin{tabular}{|c|c|c|c|c|c|c|c|}
\hline$\%$ & متوبسط & 2020 & 2019 & 2018 & 2017 & 2016 & الاولة \\
\hline 10.11 & 15.64 & 15.77 & 15.98 & 15.81 & 15.30 & 15.34 & اليابان \\
\hline 9.75 & 15.08 & 11.39 & 17.48 & 17.08 & 15.33 & 14.09 & المكسيك \\
\hline 6.76 & 10.46 & 11.66 & 11.37 & 10.17 & 9.32 & 9.79 & كوريا \\
\hline 6.67 & 10.32 & 8.51 & 11.60 & 9.50 & 13.80 & 8.20 & مصر \\
\hline 6.39 & 9.89 & 12.14 & 11.44 & 9.70 & 7.72 & 8.44 & فيتتام \\
\hline 4.78 & 7.40 & 6.19 & 7.97 & 8.98 & 7.31 & 6.52 & آيران \\
\hline 4.23 & 21.35 & 0.00 & 9.97 & 9.45 & 7.39 & 5.92 & اسبانيا \\
\hline 3.62 & 5.60 & 6.02 & 6.38 & 5.98 & 5.15 & 4.46 & هولندا \\
\hline 3.58 & 5.53 & 5.88 & 6.30 & 5.65 & 5.29 & 4.53 & إيطاليا \\
\hline 3.47 & 5.37 & 6.16 & 5.76 & 5.41 & 4.93 & 4.58 & كولمبيا \\
\hline 3.31 & 5.12 & 11.29 & 4.79 & 3.52 & 2.83 & 3.17 & الصبن \\
\hline 2.93 & 4.54 & 5.01 & 5.30 & 4.12 & 4.14 & 4.12 & الجزائر \\
\hline 2.86 & 4.41 & 4.42 & 4.81 & 4.18 & 4.45 & 4.22 & بيزو \\
\hline 2.30 & 3.55 & 3.79 & 4.01 & 3.55 & 3.38 & 3.04 & المانيا \\
\hline 29.24 & 45.22 & 53.85 & 54.25 & 42.76 & 35.08 & 40.15 & \\
\hline 100.00 & 154.67 & 162.08 & 177.41 & 155.86 & 141.42 & 136.57 & \\
\hline
\end{tabular}


منى كمال رياض عبد الكريم.: دراسة اقتصادية للسوق العالمى للذرة الصفراء مع الإثارة الىى سوق الذرة الصفراء المصري. 2003

جدول ب. الأهميــة النسبية لاهم الـــول المصدرة للأرة الصفراء من حيث الكمية المصدرة منــــها في العــــالم خلال الفترة

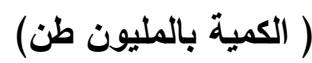

$(r \cdot r \cdot-r \cdot 17)$

\begin{tabular}{|c|c|c|c|c|c|c|c|}
\hline$\%$ & متوبسط & 2020 & 2019 & 2018 & 2017 & 2016 & الاولة \\
\hline 31.5 & 54.4 & 51.8 & 41.5 & 69.9 & 52.9 & 55.8 & آمريكا \\
\hline 17.6 & 30.5 & 34.4 & 43.3 & 23.5 & 29.2 & 21.8 & البرازِيل \\
\hline 16.8 & 28.9 & 37.0 & 36.2 & 23.2 & 23.7 & 24.5 & الارجنتين \\
\hline 13.7 & 23.7 & 27.9 & 32.3 & 21.4 & 19.4 & 17.3 & آوكرانيا \\
\hline 2.8 & 4.8 & 5.7 & 6.7 & 4.6 & 3.7 & 3.4 & رومنيا \\
\hline 2.5 & 4.4 & 4.3 & 3.5 & 4.8 & 4.1 & 5.2 & فرنساً \\
\hline 2.4 & 4.1 & 2.3 & 3.1 & 4.8 & 5.2 & 5.3 & روسيا \\
\hline 1.7 & 3.0 & 4.0 & 2.9 & 2.3 & 3.4 & 2.5 & \\
\hline 1.3 & 2.3 & 3.5 & 3.0 & 1.2 & 1.6 & 2.1 & سيربيا \\
\hline 1.0 & 1.8 & 2.6 & 2.6 & 1.4 & 1.0 & 1.3 & بلغاريا \\
\hline 8.6 & 14.8 & 16.6 & 14.3 & 14.4 & 15.8 & 12.9 & أخرى \\
\hline 100.0 & 172.6 & 190.0 & 189.3 & 171.6 & 160.0 & 152.2 & اجمالى صادرات \\
\hline
\end{tabular}

جدول \&. مصفوفة الارتباط البسيط بين السعر العالمى وأسعار التصدير لاهم الدول المصدرة للأرة الصفراء خلال

\begin{tabular}{|c|c|c|c|c|c|}
\hline \multicolumn{3}{|c|}{ (السعر بالدولار للطن ) } & \multicolumn{3}{|c|}{ 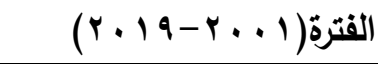 } \\
\hline أوكرانيا & الارجنتين & البرازيل & أمريكا & العالمى & السعر \\
\hline- & - & - & - & 1 & العالمى \\
\hline - & - & - & 1 & 0.90 & أمريكا \\
\hline- & - & 1 & 0.90 & 0.96 & البرازيل \\
\hline- & 1 & 0.97 & 0.92 & 0.93 & الارجنتين \\
\hline 1 & 0.94 & 0.97 & 0.91 & 0.96 & أوكرانيا \\
\hline
\end{tabular}

المصدر : جمعت وحسبت من بيانات شبكة الانترنت التابعة WWW.Trade map.org.eg

ا- العلاقة بين سعر التصدير العالمي والأمريكي للأرة الصفراء

بدراسة العلاقة السعرية بين السعر العالمى لصادرات الذرة الصفراء (كمتغير تابع )، وسعر تصدير أمريكا (كمتغير مستقل ) في المعادلة رقم (1) بالجدول رقم (0) نبين أن هناك علاقة طردية معنوية أحصائيا بينهم ، وان بزيادة سعر التصدير لامريكا بحوالي دولار للطن يؤدى الى زيادة السعر

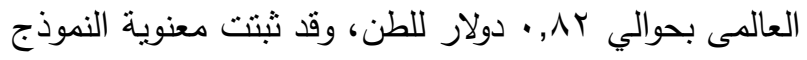

رابعا: العلاقات السعرية لاهم الدول المصدرة للأرة الصفراء

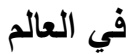
بدراسة العلاقات السعرية لصادرات الذرة الصفراء بالدولار للطن للدول سالفة الذكر مع السعر العالمى للتصدير لله

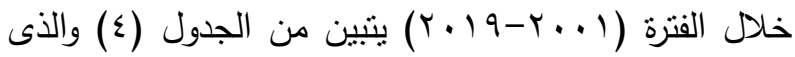
يوضح مصفوفة الارنباط البسيط بين السعر العالمى وأسعار

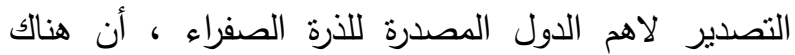
أرتباط قوى حوالى 9, · تقريبا بينهم ، الامر الذى يؤدى الى صعوبة الجمع بين السعر العالمى للتصدير (كمتغير تابع )، وأسعار التصدير لاهم الدول المصدرة وهى أمريكا، والبرازيل، والأرجنتين، وأكرانيا (كمتغيرات مسنقلة) في معادلة انحدار متعدد لتمثيل العلاقة السعرية بينهم ، نظرا لقوة الارتباط بينهم ـ الامر الذى استدعى دراسة العلاقات السعرية بين السعر العالمى لتصدير الذرة الصفراء، وكل دولة مصدرة (السالفين الذكر ) على حدا في علاقة انحدارية بسيطة وهذا ما أوضحته

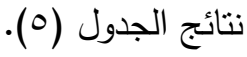




$$
\text { مجلة الإسكندرية للتبادل العلمى - (مجلد اء العدد ع) أكتوبر - ديسمبر اY.r }
$$

ترجع الى السعر التصديرى البرازيلى وأن ^^\% الباقية ترجع

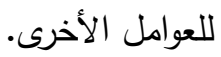

r- العلاقة بين سعر التصدير العالمي والأرجنتيني للأرة

الصفراء

بدراسة العلاقة السعرية بين السعر العالمى لصادرات الذرة الصفراء (كمتغير تابع )، وسعر تصدير الارجنتين (كمتغير مستقل) في المعادلة رقم (ب) بالجدول رقم (0) تبين أن هناك علاقة طردية معنوية أحصائيا بينهم ، وان بزيادة سعر التصدير للارجنتين بحوالي دولار للطن يؤدى الى زيادة السعر العالمى بحوالي عـ, • دولار للطن ، وقد ثبتت معنوية النموذج ككل مما يعنى صلاحية النموذج الخطى للبيانات المستخدمة في التحليل الاحصائي. كما توضح قيمة معامل التحديد والتي قدرت بنحو 7 م, • مما يعنى \%^r\% من التغيرات الحادثة في السعر العالمى ترجع الى السعر التصديرى الارجنتينى وأن ع (10 الباقية

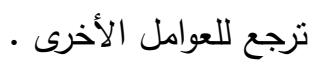

ككل مما يعنى صلاحية النموذج الخطى للبيانات المستخدمة في التحليل الاحصائي. كما توضح قيمة معامل التحديد والتي قدرت بنحو ـر, · مما يعنى ، ٪\% من التغيرات الحادثة في السعر العالمى ترجع الى السعر التصديرى الامريكى وأن · ب \% الباقية نرجع

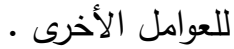

r - العلاقة بين سعر التصدير العالمي والبرازيلي للأرة الصفراء بدراسة العلاقة السعرية بين السعر العالمى لصادرات الذرة الصفراء (كمتغير تابع )، وسعر تصدير البرازيل (كمتغير مستقل) في المعادلة رقم (Y) بالجدول رقم (0) تبين أن هناك علاقة طردية معنوية أحصائيا بينهم ، وان بزيادة سعر التصدير للبرازيل بحوالي دولار للطن يؤدى الى زيادة السعر العالمى بحوالي بو, · دولار للطن، وقد ثبتت معنوية النموذج ككل مما يعنى صلاحية النموذج الخطى للبيانات المستخدمة في التحليل الاحصائي.

كما توضح قيمة معامل التحديد والتي قدرت بنحو بو بو, • مما يعنى ب9\% من التغيرات الحادثة في السعر العالمى

جدول ه. العلاقات السعرية بين السعر العالمى لتصدير الذرة الصفراء واسعار اهم الدول المصدرة له فى العالم للفترة

\begin{tabular}{|c|c|c|c|c|}
\hline & \multicolumn{3}{|c|}{ (السعر بالدولار للطن ) } & $r \cdot 19-r \ldots 1$ \\
\hline م & المتغيرات المستلقلة & المعادلة & $\mathbf{R}^{2}$ & $\mathbf{F}$ \\
\hline 1 & X ${ }_{1}$ : السعر التصديرى الامريكى & $\begin{array}{r}Y=30.8+0.82 X_{1} \\
(8.3)^{* * *}\end{array}$ & 0,80 & $(69.5) * *$ \\
\hline r & X2 : السعر التصديرى البرازيلى & $\begin{aligned} & Y=32.9+ 0.95 X_{2} \\
&(13.6)^{* * *}\end{aligned}$ & 0,92 & $(185.6)^{* * *}$ \\
\hline r & X3 : السعر التصديرى الارجنتينى & $\begin{array}{r}Y=49.3+0.84 X_{3} \\
(10.4)^{* * *}\end{array}$ & 0,86 & $(108.8)^{* * *}$ \\
\hline$\varepsilon$ & X4 : السعر التصديرى الاوكرانى & $\begin{array}{r}Y=23.2+1.05 X_{4} \\
(14.0)^{* * *}\end{array}$ & 0,92 & $(196.9)^{* * *}$ \\
\hline
\end{tabular}

WWW.Trade map.org.eg المصدر : حسبت من بيانات شبكة الانترنت التابعة

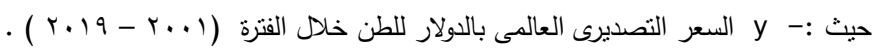
تشير إلى السعر التصديري للاولة المشار إليها بالجدول بالدولار للطن الواحد X القيمه بين الاقواس تثشير الى قيمه الححسوبه (ت )

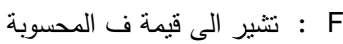

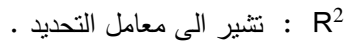

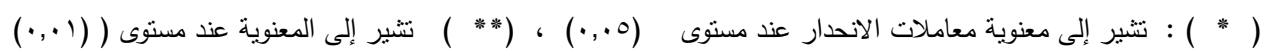




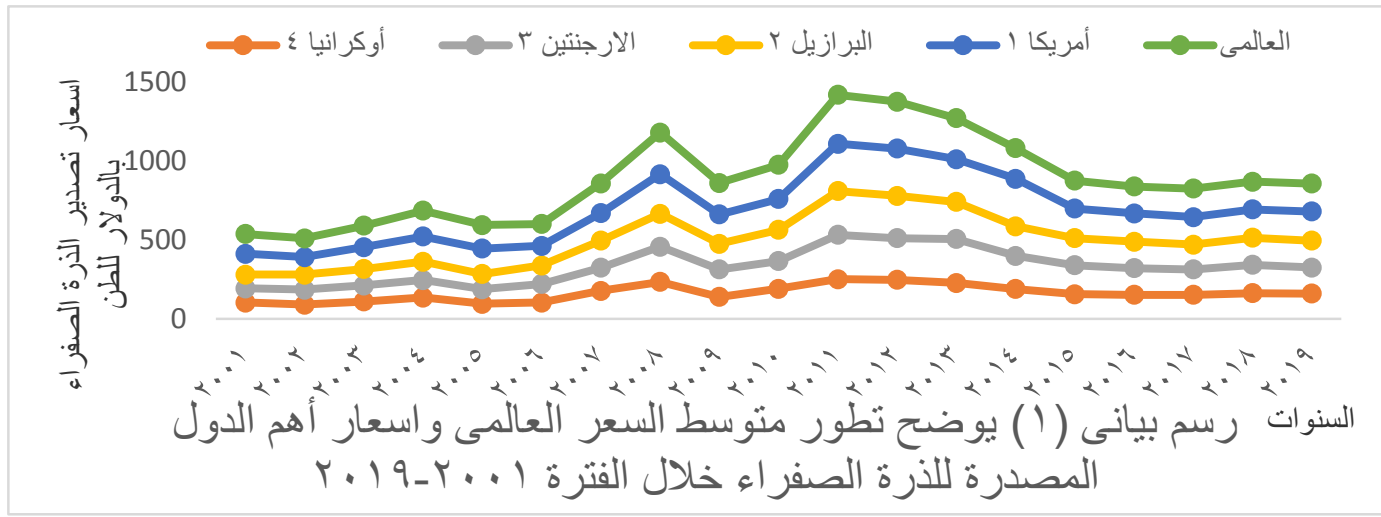

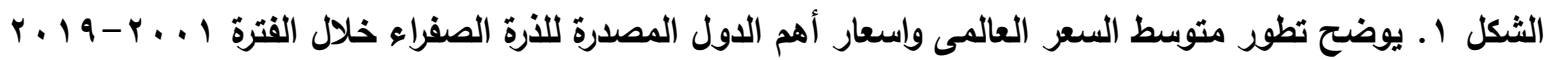
WWW.Trade map.org.eg المصدر : رسمت من بيانات شبكة الانترنت التابعة مئول

الصفراء العالمى، حيث يتخذوا نفس الاتجاه لكافة الأسعار بالدول سالفة الذكر سواء فى الاتجاه سلبا أو إيجابيا، وهو ماء التهاه يؤكد حقيقة أن سوق الذرة الصفراء فى العالم سوق أحتكار قلة يتحكم فيه هذه الدول مجتمعة بشكل أو بأخر وان كانت

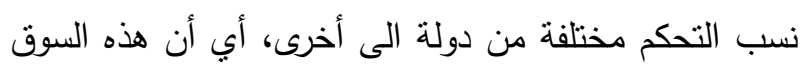

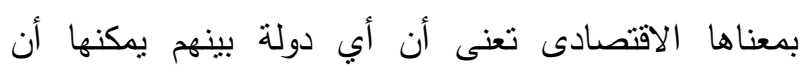
تتكاتف وتتعاون مع بقية الدول لتأكيد المصلحة المشتركة لهني بينهم وأن كانت بصفة غير رسمية. خامسا: حركة الأسعار العالمية للارة الصفراء لاهم الاول المصدرة لها خلال القترة يتضح من تطور الأسعار الثهرية للذرة الصفراء لاهم الأسواق العالمية المصدرة له والتي ذكرت سابقا خلا الفترة

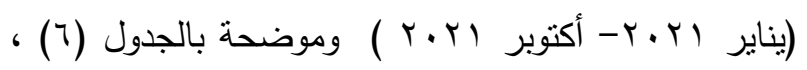

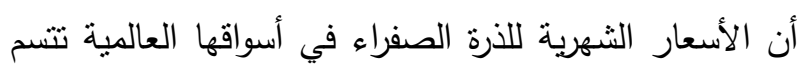

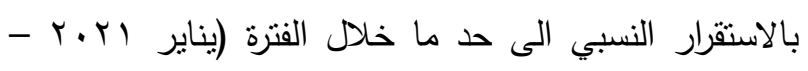
يونيو (Y.r ) ) ، ولكنها شهدت أرتفاعا ملحوظا في شهر يوليو وخاصة في أهم الدول المصدرة له وهى أمريكا، البرازيل، الارجنتين ، ثم أخذت بعدها في الانخفاض ولكن بشكل تدريجى في أمريكا والتي تعد أكبر الدول انتاجا

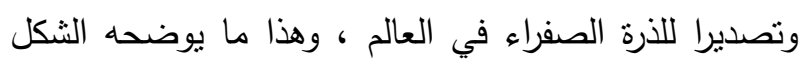
رقم (r).
ع - العلاقة بين سعر التصدير العالمي والأوكراني للازرة الصفراء

بدراسة العلاقة السعرية بين السعر العالمى لصادرات الذرة الصفراء (كمتغير تابع )، وسعر تصدير أوكرانيا (كمتغير مستقل ) في المعادلة رقم (ع) بالجدول رقم (0) ثبين أن هنالك علاقة طردية معنوية أحصائيا بينهم ، وان بزيادة سعر لئر

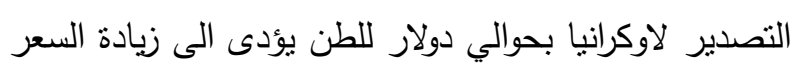
العالمى بحوالي ·, , دولار للطن ، وقد ثبتت معنوية النموذج ككل مما يعنى صلاحية النموذج الخطى للبيانات المستخدمة في التحليل الاحصائي.

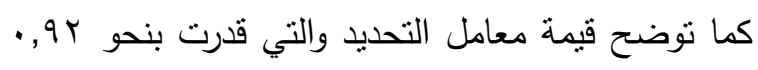
مما يعنى \%9\% من التغيرات الحادثة في السعر العالمى ترجع الى السعر النصديرى الارجنتينى وأن ^^\% الباقية ترجع

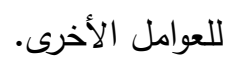
من العرض السابق يتبين أن السعر العالمى للصادرات

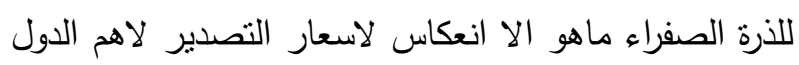
المصدرة له في العالم، وهذا ما يوضحه الثكل رقم (1) . أهم النتائج من العرض السابق يتضح من العرض السابق أن هنالك علاقات سعرية قوية بين أسعار تصدير الدول الرئيسية المتحكمة في سوق الذرة 


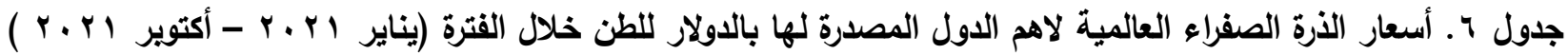

\begin{tabular}{|c|c|c|c|c|}
\hline أوكرانيا & الارجنتين & البرازيل & آمريكا & الشهور \\
\hline 272 & 246.45 & 210 & 239.95 & يناير \\
\hline 267 & 242 & 220 & 245 & فبراير \\
\hline 266.5 & 190 & 276.25 & 256.5 & مارس \\
\hline 263.5 & 233.75 & 239.25 & 250.25 & ابريل \\
\hline 261.5 & 240 & 260 & 276 & مايو \\
\hline 280 & 252 & 270 & 290 & يونيو \\
\hline 291.5 & 260.5 & 292.25 & 313 & يوليو \\
\hline 269 & 232.5 & 258.75 & 274 & آغسطس \\
\hline 260.5 & 230.75 & 251.25 & 269.5 & سبتمبر \\
\hline 273.5 & 240.75 & 264 & 267 & أكتوبر \\
\hline
\end{tabular}

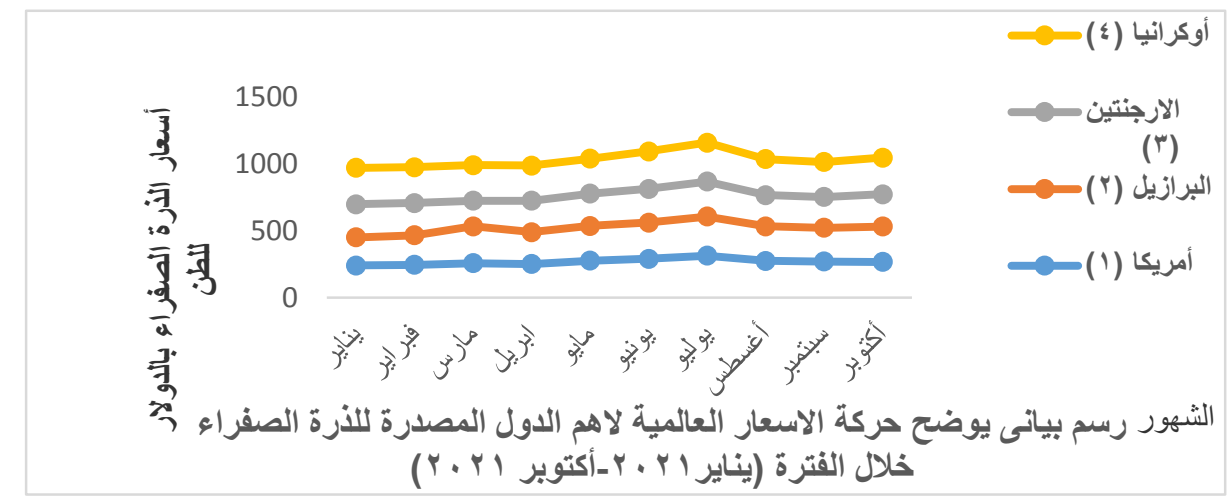

الشكل r. رسم بيانى يوضح حركة الاسعار العالمية لاهم الدول المصدرة للأرة الصفراء خلال القترة (يناير اY • r-أكتوير $(r \cdot Y)$

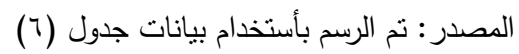

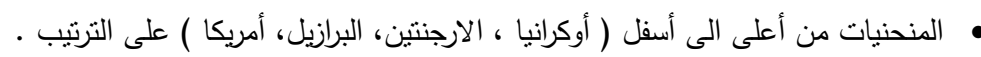

بدارسة الاتجاهات الزمنية العامه لتطور كل من أسعار وكميه وقيمة الواردات العالمية من الذرة الصفراء خلال الفترة

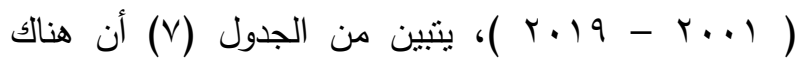
اتجاهاً عاماً متزايداً فى واردات العالم من الذرة الصفراء خله

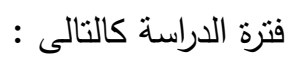
حيث تبين أن معدل النمو السنوى فى سعر وكمية وقيمة

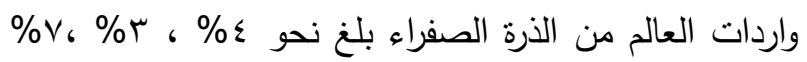
على الترنيب ، وقد ثبتت معنوية معالم النماذج، وقد اشارت قيمة ( ف ) المحسوبة إلى صلاحية النماذج المستخدمة فى
سادسا: محددات الطلب المصرى للأرة الصفراء من أهم الاول المصدرة لها للوقوف على محددات الطلب المصري للذرة الصفراء لاهم الدول المصدرة لها تطلب الأمر استعراض تطور الواردات العالمية والمصرية منها، وكذا الوقوف على التوزيع الجغرافي للواردات المصرية من أهم الدول المصدرة لها، استتبع ذلك التقدير الاحصائي لدالة الطلب المصري للذرة الصفراء من السوق العالمي.

1- تطور الواردات العالمية والمصرية من الأرة الصفراء أ- تظور الواردات العالمية من الأرة الصفراء 
منى كمال رياض عبد الكريم.: دراسة اقتصادية للسوق العالمى للذرة الصفراء مع الإثارة الى سوق الذرة الصفراء المصري. 2007 الصورة النصف لوغاريتمية وملاءمته بطبيعة البيانات الصورة النصف لوغاريتمية وملاءمته بطبيعة البيانات الإحصائية للظاهرة محل الدراسة. الإحصائية للظاهرة محل الدراسة.

كما تشير قيمة معامل التحديد أن الزمن مسئول عن

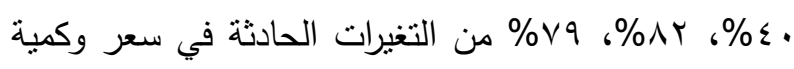
وقيمة الواردات المصرية من الذرة الصفراء . يتضح من دراسة الاتجاهات الزمنية العامه لتطور كل من

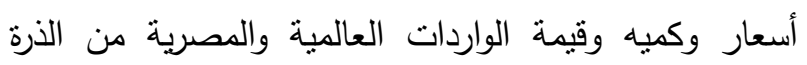

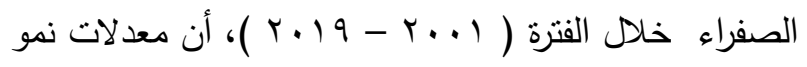
كمية الواردات العالمية بلغ نحو بـ سنويا خلال فترة الدراسة، في حين أن هذا المعدل في كمية واردات مصر بلغ نحو 0\%نويا، وهذا ما يعنى أن نصيب مصر من السوق

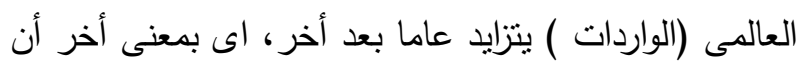

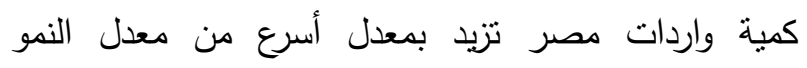
العالمى، وهو ما أوضحته معادلات الاتجاه الزمنى العام للواردات المصرية والعالمية.
كما تشير قيمة معامل التحديد أن الزمن مسئول عن

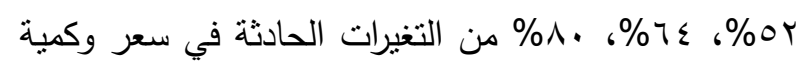
وقيمة الواردات العالمية من الذرة الصفراء .

ب- تطور الواردات المصرية من الأرة الصفراء بدارسة الاتجاهات الزمنية العامه لتطور كل من أسعار وكميه وقيمة الواردات المصرية من الذرة الصفراء خلال

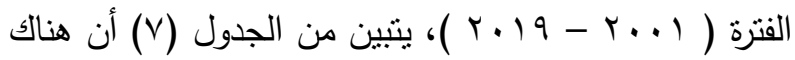
اتجاهاً عاماً متزايداً فى واردات مصر من الذرة الصفراء

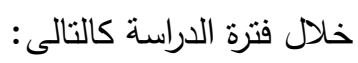
حيث تبين أن معدل النمو السنوى فى سعر وكمية وقيمة

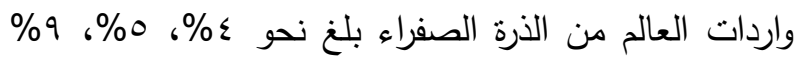
على الترتيب، وقد ثنتت معنوية معالم النماذج، وقد اشارت قيمة ( ف ) المحسوبة إلى صلاحية النماذج المستخدمة فى ولى

جدول V. الاتجاهات الزمنية لاسعار وكميات وقيمة الواردات العالميــــة والمصــرية من الذرة الصفراء خلال الفترة

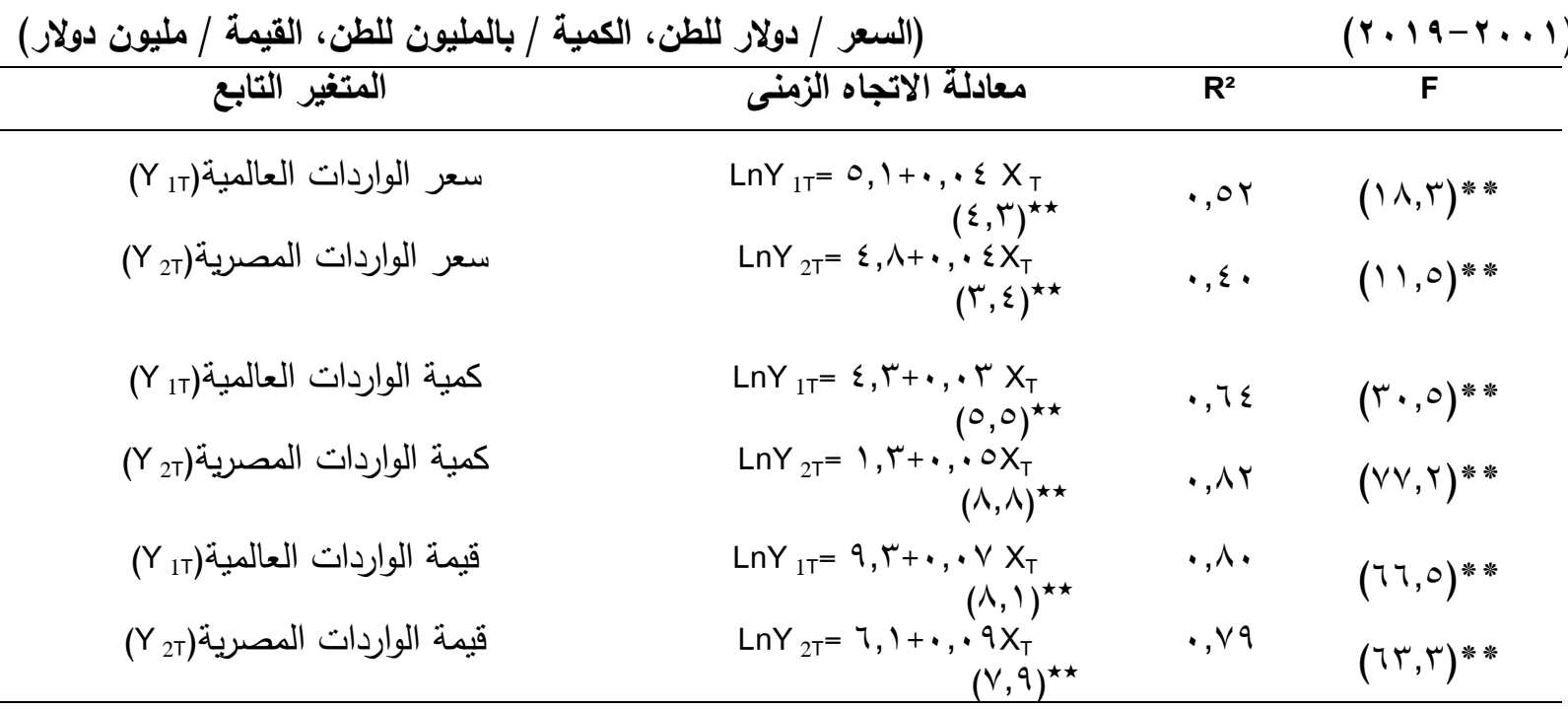

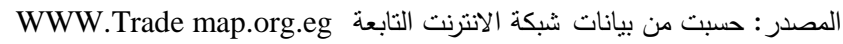

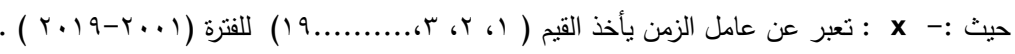
. : : $\quad \mathbf{R}^{2}$

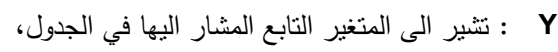

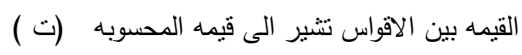

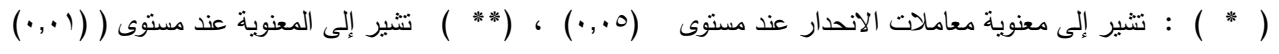


التفسيرية التى يعتقد نأثيرها على هذا العامل التابع، وذلك لتلافى الوقوع فى مشكلة القياس (مشكله الازدواج

$$
\text { الخطى). }
$$

r -إجراء الانحدار البسيط بصوره المختلفة (خطية، نصف

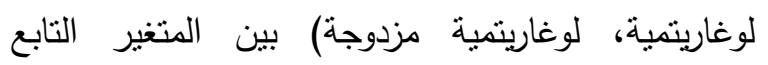
والمتغيرات المستقلة النى نم اختيارها من الخطوة السابقة كل على حده ـ وذلك لتحديد أهم المتغيرات المستقلة ذات

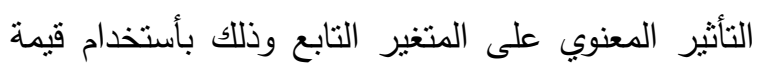

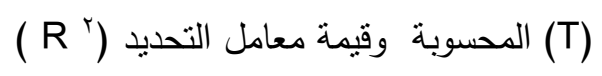

r-التقديرالإحصائي للعلاقة بين المتغير التابع والمتغيرات

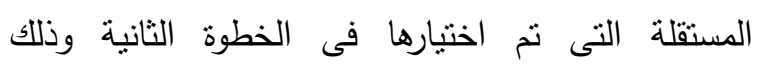

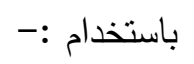

- طريقة الانحدار المتعدد بصوره المختلفة، وطريقة الانحدار

$$
\text { المتعدد المراحل بصوره المختلفة . }
$$

ع-تحديد أفضل الصور الرياضية التى تعبر عن العلاقة بين

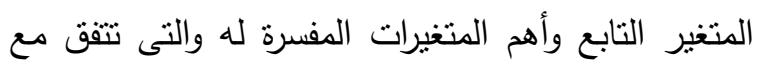

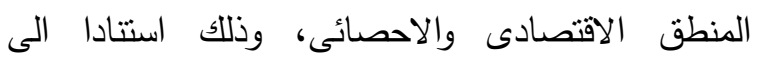
النظرية الاقتصادية، وقيمة معامل التحديد (R ) ) و وقيمة

$$
\text { ( F ) }
$$

r - التوزيع الجغرافى لواردات مصر من الذرة الصفراء من

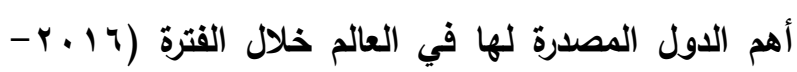
$(r \cdot r$.

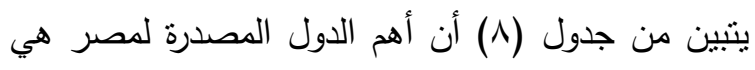

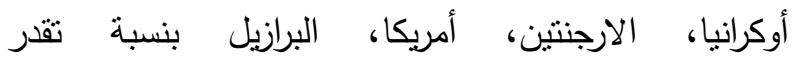

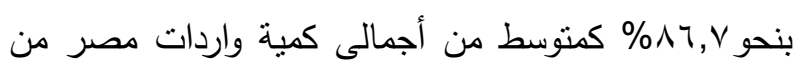

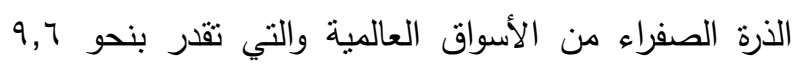

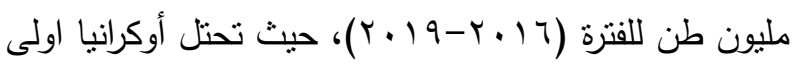

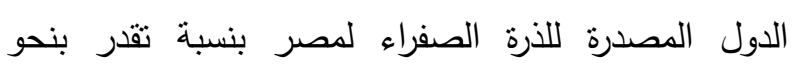

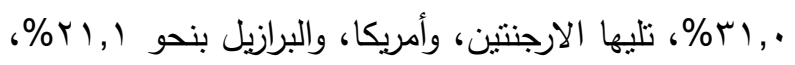

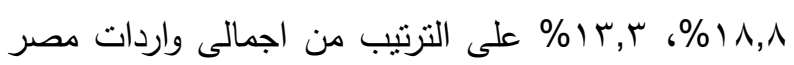

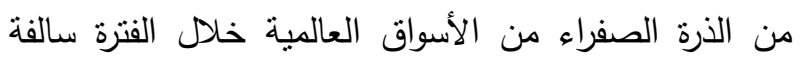
الذكر

r- التقيرالاحصائي لدالة الطلب المصرى من الذرة

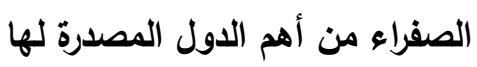
الطريقة الاحصائية المستخدمة فى تقدير دوالة الطالب الفمناء

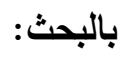
لتلافى أخطاء التقدير فقد اتبع البحث الخطوات التالية :

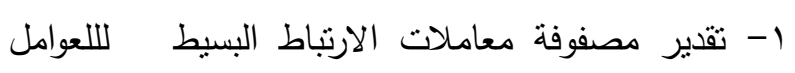

\begin{tabular}{|c|c|c|c|c|c|c|}
\hline$\%$ & 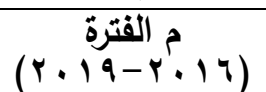 & 2019 & 2018 & 2017 & 2016 & الدول المصدرة \\
\hline 31.0 & 2.98 & 3.6 & 2.4 & 2.9 & 3 & أوكرانيا \\
\hline 21.1 & 2.03 & 2.4 & 2.1 & 1.7 & 1.9 & الارجنتنين \\
\hline 18.8 & 1.80 & 2.7 & 1.8 & 1.3 & 1.4 & أمريكا \\
\hline 13.3 & 1.28 & 1.5 & 1.4 & 1.3 & 0.9 & إلبرازيل \\
\hline 15.9 & 1.53 & 1.4 & 1.8 & 1.9 & 1 & آ أخرى ـ. \\
\hline 100.0 & 9.6 & 11.6 & 9.5 & 9.1 & 8.2 & أجمالى واردات \\
\hline
\end{tabular}

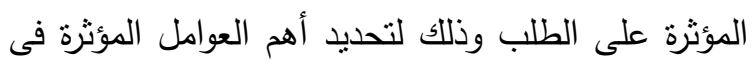

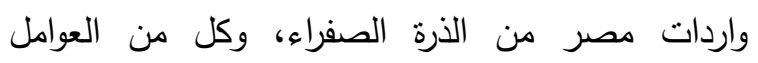

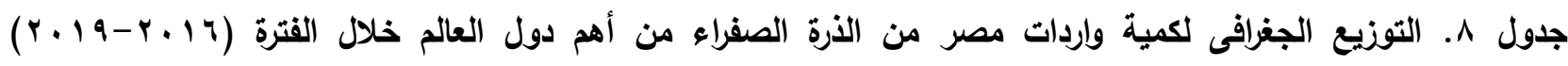

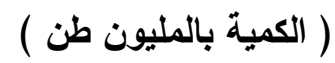


منى كمال رياض عبد الكريم.: دراسة اقتصادية للسوق العالمى للذرة الصفراء مع الإثارة الىى سوق الذرة الصفراء المصري. 2009

· : أجمالى الوزن القائم للاجاج في مصر بالطن W

(ممتاز ناجي السباعي (دكتور)، محددات الطلب الخارجي على بعض المنتجات الغذائية المصنعة من الخضر والفاكهة، جامعة عين شمس، كلية الزراعة، قسم الاقتصاد الزراعي ج . . ؟،) بدراسة دالة الطلب الدصرى من الذرة الصفراء من أهم

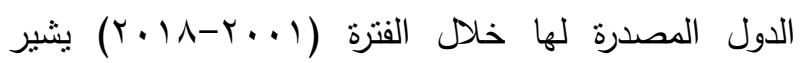

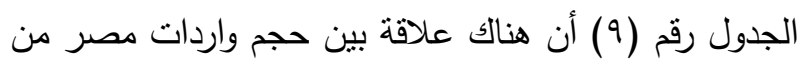

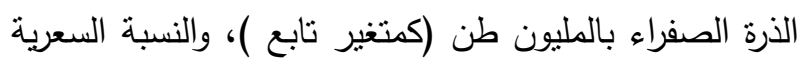

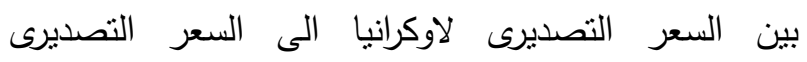

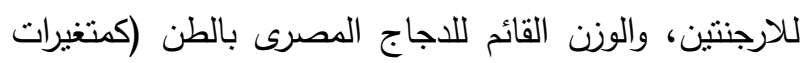

مستقلة).

حيث تبين أن هناك علاقة عكسية معنوية أحصائيا بين

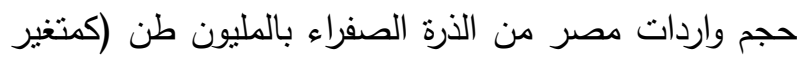

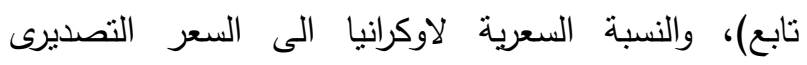
للارجنتين (كمتغير مستقل)، حيث بزيادة النسبة السعرية بحوالي ا \% يؤدى الى أنخفاض حجم واردات مصر من الذرة

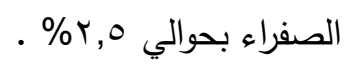

وأن هناك علاقة طردية معنوية أحصائيا بين حجم واردات مصر من الذرة الصفراء (كمتغير تابع)، والوزن القائم للاجاج المصرى بالطن (كمتغير مستقل) وهذا ما نوضحه

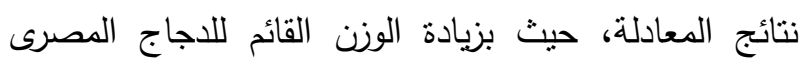

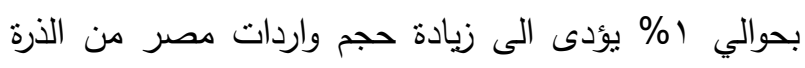

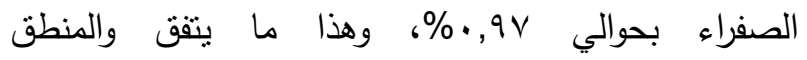
الاقتصادى، حيث بزيادة الوزن القائم للاجاج يؤدى الى زئل زيادة

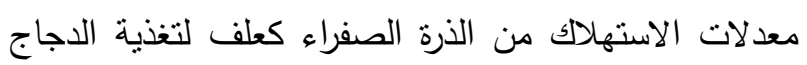

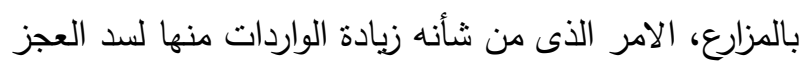

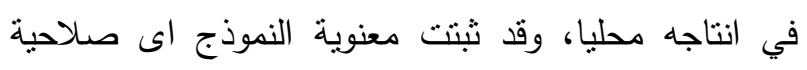
النموذج اللوغاريتمية المزدوجة للبيانات المستخدمة في التحليل الاحصائي.
النماذج الرياضية المستخدمة لتقدير دوال الطلب: لكي يحقق البحث أهدافه نم استخدام أسلوب إحصائي يتضمن تحليلات الانحدار المتعدد والمرحلي ، وذللك لنقدير

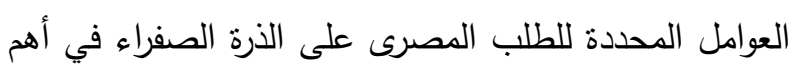

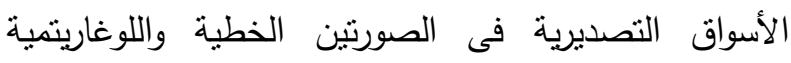

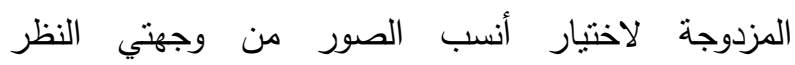
الإحصائية والاقتصادية، وللتوصل إلى أفضل الفيل المعادلات

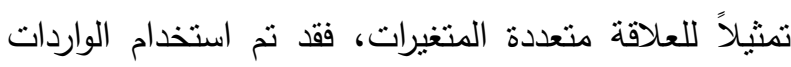

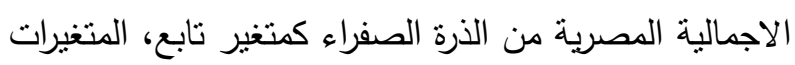

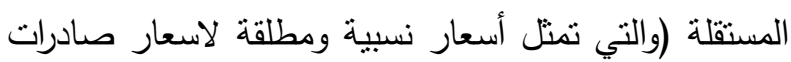

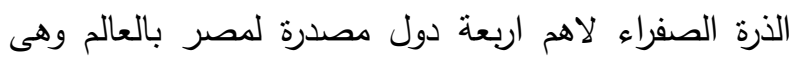

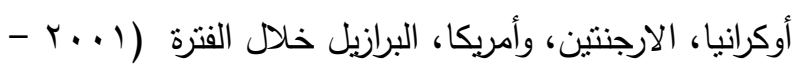

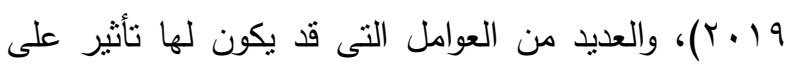

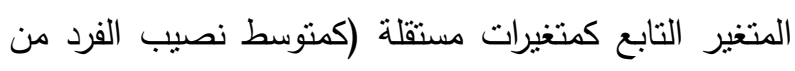

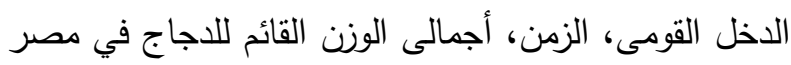

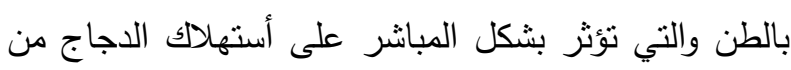

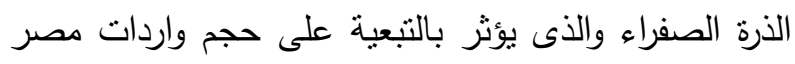

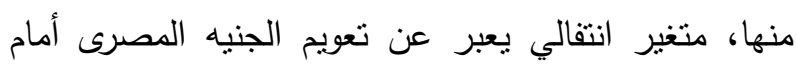

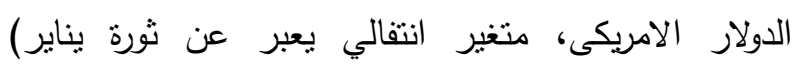
ولتلافى الوقوع في مشاكل القياس، تم أختيار أهم المتغيرات

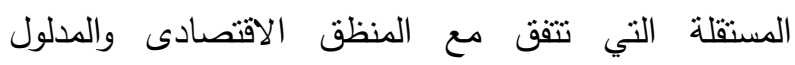
الاحصائى، والتى يمكن التعبير عنها بالنموذج الرياضي التيني

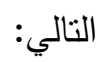
$\ln Y_{i}=\alpha+B_{11} \ln X_{1 i}+\ldots . .+B_{n} \ln X_{n i}+B_{1} \ln w_{i}+B_{1} \operatorname{lni}_{i}$

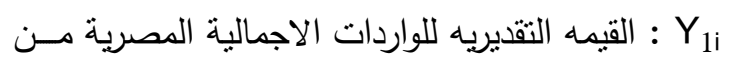

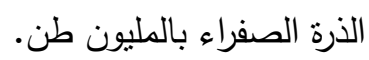
منتوسط أسعار تصدير الذرة الصفراء لاء لاهم ( X الدول المصدرة له بصورها المطلقة والنسبية . I : متوسط نصيب الفرد من الدخل القومى المصرى

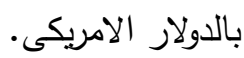


جدوله. نتائج التقلير الاحصائي لدالة الطلب المصرى من الذرة الصفراء بأهم الأسواق العالمية المصدرة لها خلال الفترة

\begin{tabular}{|c|c|c|c|}
\hline دالة الطلب & مرونة النسبة & $\mathbf{R}^{2}$ & F \\
\hline $\begin{array}{r}\operatorname{Ln} Y=1.1-2.5 \operatorname{Ln} P x 1 / P \times 2+0.97 \operatorname{Ln} w \\
(-2.5)^{* *}(4.9)\end{array}$ & $2.5-$ & 0.73 & 20.1 \\
\hline
\end{tabular}

$$
\begin{aligned}
& \text { WWW.Trade map.org.eg المصدر : حسبت من بيانات شبكة الانترنت التابعة }
\end{aligned}
$$

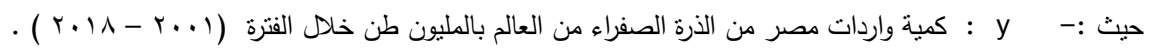

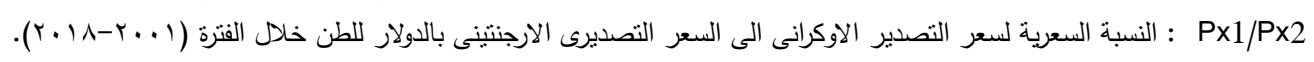

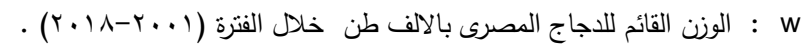

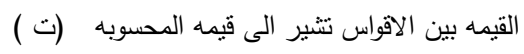

$$
\begin{aligned}
& \text {. : : : : : : }
\end{aligned}
$$

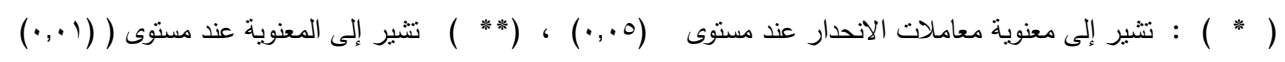

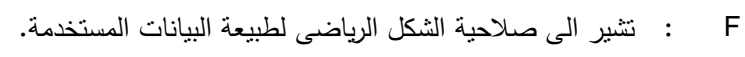

• دعم مستلزمات انتاج الذرة الصفراء وبصفة خاصة توفير تقاوى عالية الإنتاجية الفدانية بسعر مناسب للمزارع الذى دوم يعانى من أنخفاض مستوى دخله .

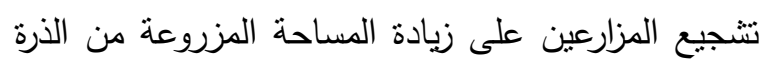
الصفراء بأستخدام أصناف عالية الجودة، وذلك من خله لهادة

$$
\begin{aligned}
& \text { مركز الزراعات التعاقدية بوزارة الزراعة } \\
& \text { r- السياسات التجارية: }
\end{aligned}
$$

• وضع اليات من شأنها تكنل مصر مع الدول المنافسة لها

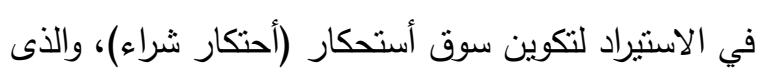
يجعلها قوة أمام سوق الاحتكار القلة العالمى الذى بتحكم

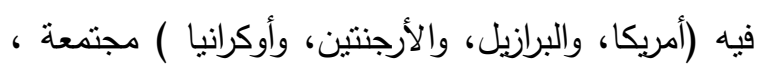

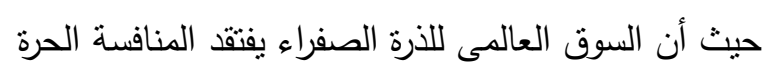
، الامر الذى يجعل الدول المستوردة لها تتأثر بشكل كبير لاى تغيرات عالمية لسوق الذرة الصفراء.

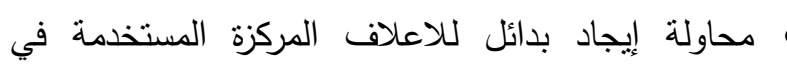
تغذية الدواجن محليا من شأنها تقليل حجم الواردات المصرية من الذرة الصفراء .
كما تشير نتائج مرونات النسبة السعرية لدالة الطلب محل الدراسة، الى أن أوكرانيا كدولة مصدرة للذرة الصفراء

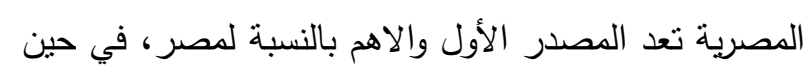

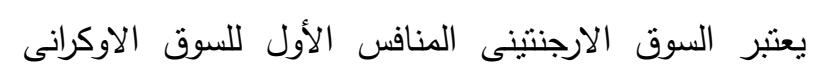

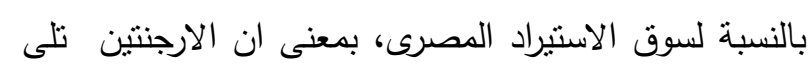
أوكرانيا من الأهمية في تصدير الذرة الصفراء لمصر حيث تمثل مرونة النسبة السعرية لها - V, •. كما تشير قيمة معامل التحديد سV, • الى أن بV\% من التغيرات الحادثة في حجم الواردات المصرية من الذرة

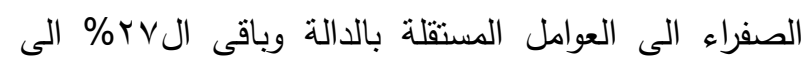

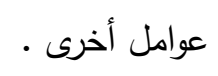

سابعا: بعض السياسات الإنتاجية والتجارية والسعرية المقترحة في مصر لمواجهة تغيرات السوق العالمى للارة الصفراء من واقع دراسة السوق العالمى مع الإثارة للسوق المصرى للأرة الصفراء . 1- السياسات الإنتاجية: • التوسع في زراعة الذرة الصفراء بالاراضى الجديدة في 
منى كمال رياض عبد الكريم.: دراسة اقتصادية للسوق العالمى للذرة الصفراء مع الإشارة الى سوق الذرة الصفراء المصري. 2011 ايمان فخرى يوسف، دراسة أقتصادية للسوق العالمى للذرة ب- السباسات السعرية : (1) الثامية، دكتوراه، قسم الاقتصاد، كلية الزراعة، جامعة

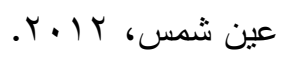

شادية محمد سيد ناصر، (واخرون ) ) ، دراسة أقتصادية لمحصول الذرة الرفيعة الصيفية بمحافظة أسيوط، مجلة

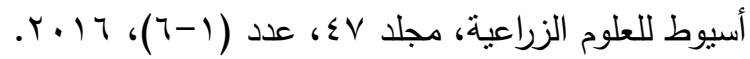

$$
\text { مجلس الحبوب الدولي IGC (نشرات وتقارير ) }
$$

وضع سعر ضمان للذرة الصفراء يشجع المزارعين على

$$
\text { زيادة المساحات المزروعة من الذرة الصفراء . }
$$

تشكيل سوق أستحكار من اهم الدول المستوردة (الموضح أعلاه)، الذى يجعلها قوة قادرة على مساومة سوق الاحتكار القلة العالمى في وضع سعر مناسب لاستيراد الذرة الصفراء من أهم الدول المصدرة لها. محمد كامل ريحان،(دكتور)، الطرق الكمية في العلوم

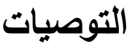
الاقتصادية (تطبيقات عملية)، دار المكتب العربى

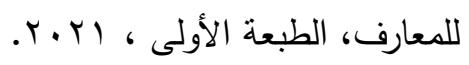

ممناز ناجي السباعي ، محددات الطلب الخارجي على بعض المنتجات الغذائية المصنعة من الخضر والفاكهة، دكتوراه ، جامعة عين شمس، كلية الزراعة، قسم الاقتصاد

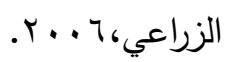

نجوى عبد المنعم مصطفى، (واخرون)، أثز السياسات السعرية على محصول الذرة الصفراء في مصر ، ، مجلة

الإسكندرية للعلوم الزراعية، مجلد با7، عدد(1)

$$
\text { . r. r. }
$$

وزارة الزراعة الامريكية ( الإحصاءات المنشورة ) وفاء أبو بكر ، دراسة أقتصادية تحليلية لانتاج وتنويق الذرة الثامية في مصر، (ماجستير)، قسم الاقتصاد، كلية

$$
\text { الزراعة ، جامعة عين شمس، } 7 \text { ×. . r. }
$$

يحى عبد الرحمن يحى، (واخرون) ، سلسلة القيمة لمحصول الذرة الصفراء ودور الجمعيات التعاونية الزراعية، المجلة المصرية للبحوث الزراعية ، المجلد 91، عدد(ب)،

$$
\text { . r. r. }
$$

H\&Q , Microeconomic theory (A Mathematical approach ), Mc Graw- Hill , Book company , Inc . New York, Toronto, London , 1958. WWW.Trade map.org.eg

ا ـ التوسع في زراعة الذرة الصفراء بالاراضى الجديدة في

r. دعم مسنلزمات انتاج الذرة الصفراء وبصفة خاصة توفير تقاوى عالية الإنتاجية الفدانية بسعر مناسب للمزارع الذى يعانى من أنخفاض مستوى دخله .

r. تشجيع المزارعين على زيادة المساحة المزروعة من الذرة الصفراء بأستخدام أصناف عالية الجودة ، وذلك من لهادة خلال مركز الزراعات التعاقدية بوزارة الزراعة ع. وضع اليات من شأنها تكنل مصر مع الدول المنافسة لها في الاستيراد لتكوين سوق أستحكار (أحتكار شراء)، والذى يجعلها قوة قادرة على المساومة أمام سوق الاحتكار القلة العالمى الذى يتحكم فيه (أمريكا، والبرازيل، والأرجنتين، وأوكرانيا ) مجتمعة ، في وضع سعر مناسب لهب لاستيراد الذرة الصفراء من أهم الدول المصدرة لها. ه. محاولة إيجاد بدائل للاعلاف المركزة المستخدمة في لاهي تغذية الدواجن محليا من شأنها تقليل حجم الواردات المصرية من الذرة الصفراء . 7. وضع سعر ضمان للذرة الصفراء يشجع المزارعين على زيادة المساحات المزروعة من الذرة الصفراء .

\section{المراجع}

إسماعيل محمد هاشم،(دكتور)، علم الاقتصاد، دار الجامعات

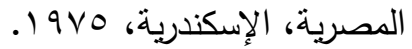




\title{
ABSTRACT \\ An Economic Study of the World Yellow Corn Market with Reference to the Egyptian Yellow Corn Market
}

\author{
Mona Kamal Ryad Abd ElKareem
}

The research mainly aimed to study the nature and description of the global market for yellow maize, to identify the type and composition of the market and who controls the clarity of its price policies, so that decision makers can develop appropriate mechanisms for trade and production policies.

\section{The most important conclusions:}

1- That the global yellow maize market is an oligopoly market, and that America, Brazil, Argentina and Ukraine represent the informal cartel, whose average amount of exports represents about $66 \%$ of the world's exports of them.

2- The growth rates of the amount of global imports amounted to about $3 \%$ annually during the study period, while this rate in the amount of Egypt's imports amounted to about 5\% annually, and this means that the amount of Egypt's imports increases at a faster rate than the global growth rate, which is indicated by the equations of The general time trend of Egyptian and international imports.

3- Ukraine, as an exporting country of yellow corn, is the first and most important source for Egypt, while the Argentine market is considered the first competitor to the Ukrainian market in relation to the Egyptian import market, where the price elasticity of it is estimated - 0.7.

Key words : Corn - Prices - Markets - World 